\title{
Increasing Students' Interest in Reading in a Foreign Language: A Focus on Skimming and Scanning
}

\author{
Tanju Deveci \\ Khalifa University of Science and Technology, Abu Dhabi, UAE
}

\begin{abstract}
University students ought to read extensively in order to succeed in their studies. Despite this, not all students have the necessary skills to be efficient readers. The situation can be even more serious for students pursuing a college degree in a foreign language. A variety of instructional activities can help students acquire reading skills essential for academic success. However, if students lack the interest and motivation for reading, all efforts will be futile. This may also have far-reaching effects reducing their aptitude for learning at large. Considering the significant the role motivation plays in learning in general and reading in particular, this paper focuses on skimming and scanning as key reading skills. But first reading is defined, and a variety of approaches to teaching reading skills are described. Potential learner problems with reading in general and skimming and scanning in particular are identified. Possible ways of reducing these problems are discussed. It is also emphasized that helping students acquire reading skills is not the responsibility of language instructors alone. Rather, every educator, may it be a teacher, an instructor or a professor, needs to assume an active responsibility in guiding students through texts they are required to read.
\end{abstract}

Keywords: Reading, Motivation, Skimming, Scanning, Learner problems, Student interest

\section{Introduction}

Reading is a key skill for university students since many tasks assigned by university professors are heavily based on reading. However, reading can be a challenge for new university students for a variety of reasons. The challenge can be even more formidable for students who are required to read in a foreign language. Unless they are helped to tackle the sources of these challenges, their well-being will be at risk. In order to prevent this, it is necessary for educators to be well-informed about what reading really is, how we read different texts, and the ways in which students' interest in and skills of reading can be increased.

It is, therefore, useful first to define what reading is. In basic terms, reading can be defined as "the capacity to gain meaning from written language" (Gallagher \& Kirk, 1991, p. 64). Similarly, Deehant (cited in Macceca, 2013) defines it as "a visual process that begins with one's ability to use one's vision to interpret graphic symbols" (p. 4). According to Macceca (2013), therefore, for a person to be able to read he/she ought to be able to "visually distinguish each letter, have a visual memory for each letter, and recode those letters so that [he/she] can recreate the letters, pronounce the letters, or associate sound with the letters" (p. 4). However, she also points out that for comprehension we must be able to understand what the word means, which requires us to be able to "cognitively process the words by drawing meaning from [our] own experiences and knowledge to understand the author's message" (p. 4).

What these definitions suggest is that reading is more than seeing words or symbols on paper, a screen or other types of surfaces. It requires one to make sense of the visual stimulant. However, we cannot lose sight of the fact that reading may also involve the sense of touch. Consider how the visually impaired read. In either case, though, reading does not necessary mean we give all our attention to every single word in a text. It is highly possible that the text we need to read contains words or symbols that may not require our complete attention. However, we may also be required to read rather intensively, as is in the case of exam questions or instructional manuals. This entails that we know different kinds of materials we read in our daily lives as well as those for academic purposes. Only in this way can we identify different skills that enable us to comprehend what 
we read. Gallagher and Kirk (1991) give the examples of reading a single-word traffic sign or a restaurant menu versus a newspaper, a novel or a technical manual. Depending on what we read, reading can be argued to be a dialogue with the author. For this dialogue to be effective, the reader ought to form questions that would help $\mathrm{him} / \mathrm{her}$ "anticipate meaning, search for information, respond intellectually and emotionally, and infer ideas from and explain further content of the text" (Maccea, 2013, p. 4)

Willis (1996), on the other hand, lists the reading skills necessary for a variety of texts as follows: a) recognising words and phrases in scripts, b) using one's knowledge of the outside world to make predictions about and interpret a text, c) retrieving information in a passage, d) distinguishing the main ideas from subsidiary information, e) deducing the meaning of unknown words, ignoring unknown words that are redundant, f) understanding the meaning and implications of grammatical structures, g) recognising discourse markers, h) recognising the function of sentences - even when not introduced by discourse markers, i) understanding relations within the sentence and the text, $\mathrm{j}$ ) extracting specific information for summary or notetaking, k) skimming to obtain the gist, and recognising organisation of ideas within the text, and l) understanding implied information and attitudes and how to use an index, layout, use of headings, etc.

\section{Skimming and Scanning}

The effective use of the above-mentioned skills may be a challenge for students with no interest in reading. One way of increasing student interest in reading is enhancing their skimming and scanning skills through interesting activities. These skills are necessary for quick and efficient reading. Considering the heavy load of reading university students have, effective use of these skills will reduce student stress and create greater motivation for learning. But what do these skills really mean?

A basic definition of skimming is "running one's eyes over a text to get the gist of it" (Grellet \& Seal cited in Pritchard \& Nasr, 2004, p. 428). Depending on our purpose for reading, there are three main types of skimming (Konstant, 2011). The first one is "skimming to overview", whose purpose is to get an outline of what the material is about. This type involves our attention to structure of the material rather than its content. The second one is "skimming to preview." We normally use it when we know we are going to re-read the material. We do this kind of skimming to collect as much background information as possible, avoiding spending too much on it. The last type is "skimming to review," which is used to re-familiarize ourselves with the content, and it takes place when we have already read the material. International Maritime Organization (2009) notes that skimming is a key skill for students who often need to read a text quickly to get the general meaning. By moving their eyes quickly along the text, they learn to read whole phrases rather than separate words, which in turn increases their reading speed and comprehension.

After having skimmed the text, the reader can go through the text very quickly to find particular information such as a date, and the name of a researcher. When doing this, he/she is selective in choosing what to focus on depending on the information needed. This is called scanning. Scanning is very useful for finding information in indexes and catalogues. To scan a text we can use the same strategies as skimming. That is, we can look at the centre and go over the rest of the text until we see the piece of information we are looking for. We can also read the text as quickly as possible looking for the information we need. There is no need to stop for words we do not understand, or worry about their meanings since we are looking for a single piece of information. If we are answering questions about the text, we should remember that the words used in the questions might be synonyms for some of the words in the text.

Before starting to read a text, we normally make sure that it is the topic of our interest. To do this we use certain skimming strategies like looking at the title and making inferences, looking at the pictures and graphs, repeated words and the centre section of the text. These things tell us what kind of text it is and if we should read it. Naturally, university students are not in a position to decide whether they should certain texts like those they are given during examinations. However, skimming can still help them since having understood the topic or text 
type they can build expectations or use their world knowledge about the topic, which allows them to follow the text easier.

Despite the differences between skimming and scanning, it is natural to make use of them together. We may skim a text to see if it is worth reading and then scan it to note down the things which we particularly want to remember.

\section{Learner Difficulties with Reading}

Students may have a variety of difficulties with reading in general. These include, but are not limited to, the following:

a- Unlike their native language (L1), learners of English as a foreign language (EFL) may not know thousands of words in the target language, and they may not be as good at handling new grammatical structures as native speakers of English (NSEs). This can easily lead to a lack of interest and motivation. I observed this with my students, too. Especially elementary students I taught tended to complain about extra reading texts. They preferred reading the texts in their course-book, and they sometimes avoided any texts above their exact level. Therefore, it may be difficult to use authentic texts with such students unless the task is simplified.

b- For students who do not use the Latin alphabet, it may be quite difficult to get used to the letters and moving the eye from left to right.

c- If students do not read enough in their own native language, it may be difficult for them to read in English as a foreign language. For most students, learning a foreign language means to learn the grammar and vocabulary. These students may prefer being given the information in the text rather than get it themselves. Reading skills may not be important for such students.

d- If the text is culturally irrelevant to students, they will have a very difficult time understanding it, if any at all.

e- If students know the rules of their L1, they are more likely to be receptive to improving their reading skills. Unfortunately, this was not usually the case for some of the students I taught in the past.

f- From my experience, I can say there are two types of students as regards to their attitude to reading. First, there are those who want to read only academic texts since they believe they are at university to learn English for academic purposes. Then there are also those who refrain from reading anything academic or "serious" since they find them too difficult.

g- Some students' lack of understanding of organization in a text will also easily prevent them from understanding it. Such students will have difficulty in following ideas in the text and therefore may end up in a chaos.

\section{Learner Difficulties with Skimming and Scanning}

Just as students may have difficulties with reading in general, they may also face challenges with skimming and scanning. Some of these are as follows:

a- Some students tend to translate every single word they see with the hope that this is the only way they can understand what they are reading. Some adopt a similar approach with new language structures as well. For students who do not have adequate training prior to their university studies on how we read in our daily lives as well as for academic purposes, it is more difficult to acquire different reading skills. They may simply be resistant, or fail to make sense of the logic behind skimming and scanning. Alternatively, for language learners it may be the case that they perform these skills in their L1, but cannot transfer them to the new language they are learning. When they are confronted with English texts, they may simply forget what they normally do in their L1, and instead attempt to understand every single word in the texts they are required to read. 
b- Some students may start reading the whole text before looking at the title, pictures, or questions. This prevents them from predicting the content of the text and raising their schemata relative to the content as well as lexis.

c- Some students may fail to have expectations before starting to read.

d- During an examination, some students may not read the questions first. Rather, they may start reading the text as soon as they receive it. Their failure to analyse the questions first often cause them to pay attention to unnecessary details, which in turn causes time-constraints. Therefore, they have difficulty answering all the questions, or at least some of their answers will be wrong. Added to this is the stress they suffer from trying to finish the exam on time.

\section{Approaches to Teaching Reading Skills}

There are different approaches and models to teaching reading. One of these is suggested by Aebersold and Field (1997) who summarize their model as follows:

a. Study of the layout

b. Making hypotheses about the contents and function

c. Anticipation of where to look for confirmation

d. Skimming through the text

e. Confirmation or revision of one's guesses

f. Further prediction

g. Second reading for more detail

This approach lends itself to skimming-scanning activities. By studying the layout and making predictions about the content students see if they need to read it at all. They make use of skimming. If it is the right kind of text, they anticipate where to look for the information they want. Therefore, they do not need to read every sentence or paragraph. By scanning they directly go to the place where they think the information is.

Another model is "the methodological model" by Harmer (1991). The stages of this model are as follows:

a. Lead-in: The students and the teacher prepare themselves for the task and familiarise themselves with the topic of the text.

b. Teacher directs comprehension task: The teacher makes sure that the students know what they are going to do. He explains and directs the students' purpose for reading.

c. Students read for task: They read the text to perform the task the teacher has set.

d. Teacher directs feedback: The teacher helps students to see if they have completed the task successfully and find out how well they have done.

e. Teacher directs text-related task: The teacher organises a follow-up task based on the content or lexis of the text.

On the other hand, in their communication intensive approach to teaching close reading to science students, Lapp et al. (2013, p. 112) suggest the following way of helping students acquire reading skills:

a. First reading: The teacher explains the purpose and process of reading the text. He/she provides a prompt such as "What is the general information the author is sharing about $X, Y, Z$ ?" Students start reading the text for the first time, and they annotate the text while reading.

b. Chatting and charting: Students compare their annotations and responses with their peers. The teacher monitors the conversation between students. 
c. Reading again: The teacher asks additional questions requiring students to read the text again as many times as necessary.

d. Chatting and charting: Conversation is held again after each return to the text. This time, student responses are expected to deepen as a result of greater understanding.

e. Independence: At this stage, students work either independently or with their peers to illustrate their understanding of the text. They could do this in a variety of ways such as writing an argumentative paper based on their text, creating a multi-media project or a collaborative poster.

Another approach to increasing students' interest in reading is using K-W-L charts proposed by Ogle (1986). "K" refers to what students know about a particular topic, "W" to what they want to learn about it, and "L" to what they have learned after the completion of the reading task(s). For this purpose, the chart in Figure 1 below can be used. Students may be reluctant to do this initially due to their lack of active learning experience. However, after teacher guidance and facilitation, they will be able to develop an intuitive habit of doing this for different subject matters as well without having to fill in the chart in its physical form. Their increased awareness of content matter and readiness for the reading task through brainstorming sessions will surely boost their motivation (Warrington, 2005).

\begin{tabular}{|c|c|c|}
\hline K & W & L \\
\hline What I Know & What I Want to Know & \\
\hline & & \\
\hline
\end{tabular}

Fig. 1. K-W-L Chart

Related to "K" (What I Know), Barton and Jordon (2001) warn that the teacher needs to make sure that what students know ought to be accurate. They note that it is possible that students have certain misconceptions about topics they are to study. Both the teacher and students need to work hard to enable students to confront and resolve these misconceptions. The first step for this is to identify what the students know, or what they think they know. One way to do this is " "the extended anticipation guide," suggested by Duffelmeyer \& Baum (cited in Barton \& Jordan, 2001). The extended anticipation guide requires students to identify their beliefs before they start reading. Then they are asked to justify these ideas, or revise them in light of the information they have acquired doing the reading task. Barton and Jordan (2001) warn that it may be difficult for students to let go of their misconceptions, so the teacher needs to be ready to facilitate the process for the students both psychologically and intellectually.

\section{Awareness Raising Activities for Skimming and Scanning}

Students' awareness relative to skimming and scanning can be increased in a variety of ways. Some of these are as follows:

a. The teacher asks students what kind of advertisements there are in newspapers and how often they consult small adverts in their own language. Then, they are told that they will look at some adverts in English to answer some questions. They are shown the questions beforehand so that they scan the text only to extract the information which the questions demand without worrying about the sections of the text they have difficulty with. This activity will help students overcome the problem of reading irrelevant parts. 
b. For higher level of students the following skimming activity can be useful: Students are given some titles which they have to match with paragraphs of a text. The teacher asks them if they always see the same words in the titles when they read the text. He/she elicits the possible synonyms of the words in the titles and tells students when they read they should also be mindful of these synonyms. This activity will help them deal with their problem of looking for the same words in the titles in the text.

c. Intermediate or upper-intermediate students can be told that they are going to go on a holiday in summer and given some questions they ask themselves. Then the teacher shows a long text in students' language. He/she asks students if they really need to read every word to answer their questions. The answer would, hopefully, be 'No'. He does the same with an English text. This time students will go on an English course in the summer, and they have some questions about the place. They read to answer their questions in the same way. Again for low-level students this activity may lead to intensive reading. To avoid this, the teacher can simplify the language by omitting very specific world knowledge or things that are not very important to the task.

\section{Practice Activities for Skimming and Scanning}

After students' awareness is raised about how skimming and scanning work, they should be provided with ample opportunities for practicing these. Some ways in which this can be done are as follows:

a. Harmer's model can be used to scan a text. Students can be shown some pictures of people doing the same job and by discussing it they prepare themselves for the topic and build expectations. Then the teacher tells them to choose one of them and read the text to fill in a chart by scanning the text. Here they know what they have to do. Then they perform the task and have feedback on how well they have done. Finally, teacher asks them to find similarities between them.

This activity encourages them not to read every word in the text. To see if their expectations are met in the text, they look for specific information in the text. By building expectations, they increase their interest in reading the text.

a. To practise skimming, the teacher can give some short texts to students and ask them to match them with certain titles. Short newspaper articles will serve this well. This activity could be done with any level of students. However, the teacher might need to simplify or change the headlines in order to provide some clues. If there is a big similarity between the choices students would tend to read intensively. This should be borne in mind when choosing the headlines.

b. To read for general understanding, the following skimming activity can be done with lower level of students: Students are given some occupation names (doctor, actress etc.) and asked to brainstorm related vocabulary for each of them. Then teacher gives out the pictures of people who describe their occupations naming it. Students read the descriptions to match the pictures with the occupations. This activity helps students generate vocabulary about the text and look for these key words in the text.

\section{Conclusion}

Reading is a skill required for students' academic and intellectual development. The effective use of reading skills enhances students' overall well-being by enabling them to cope with the hardships of university life. However, due to the increased sensory stimuli as a result of technological developments, there seems to be a decrease in students' motivation for reading in general. This is often caused by students' misconception that reading takes too much time, and they can learn the same content through other mediums such as videos that are readily available on the Internet. Although this may be true to a certain extent, such mediums cannot, and should not, replace reading itself. Otherwise, students' imagination and thinking skills are likely to be affected in a negative way. The situation may even be more challenging for students pursuing their education in a different 
language from their native language. Confronted by a variety of other challenges, these learners' motivation may be hampered more severely. Unless they are guided by their instructors, their learning experience may not be a fruitful one, decreasing their chances of developing an aptitude for learning throughout their lives. Therefore, every effort should be made to help learners of any level to tackle their problems with reading, and increase their motivation for greater engagement in reading activities. As Macceca (2013) puts it, this should not be perceived as the task of language teachers per se. Content teachers should also assume the responsibility to guide their students through various reading materials they assign their students. I hope that different approaches to teaching and practicing reading described above provide at least some insight into how this could be achieved.

\section{References}

[1] Aebersold, J. A \& Field, M.L. (1997). From reader to reading teacher. Cambridge: Cambridge University Press.

[2] Barton, M. L., \& Jordan, D. L. (2001). Teaching reading in science: A supplement to teaching reading in the content areas: If not me, then who? ( $2^{\text {nd }}$ Edition). Aurora, CO: McREL.

[3] Gallagher, R., \& Kirk, U. (1991). The neuropsychological determinants of functional reading, writing, and arithmetic. In D. E. Tupper \& K. D. Cicerone (Eds.) The neuropsychology of everyday life: Issues in development and rehabilitation (pp. 45-92). Dordrecht, the Netherlands: Kluwer Academic Publishers. https://doi.org/10.1007/978-1-4613-1511-7_3

[4] Harmer, J. (1991). The practice of English language teaching. UK: Longman.

[5] International Maritime Organization (2009). Model course 3.17: Maritime English (2 ${ }^{\text {nd }}$ edition). London: IMO.

[6] Konstant, T. (2011). Successful speed reading. London: Hodder Education.

[7] Lapp, D., Grant, M., Moss, B., \& Johnson, K. (2013). Students' close reading of science texts. The Reading Teacher, 67, 2, 109-119. doi:10.1002/TRTR.1191 https://doi.org/10.1002/trtr.1191

[8] Macceca, S. (2013). Reading strategies for science. Huntington Beach, USA: Shell Education.

[9] Ogle, D. (1986). K-W-L group instruction strategy. In A. S. Palincsar, D. S. Ogle, B., F. Jones, E. E. Carr (Eds.). Teaching reading as thinking (pp.11-17). Alexandria, VA: Association for Supervision and Curriculum Development.

[10] Pritchar, R. M. M., \& Nasr, A. (2004). Improving performance among Egyptian engineering students: Principles and practice. English for Specific Purposes, 23, 425-445. https://doi.org/10.1016/j.esp.2004.01.002

[11] Warrington, S. D. (2005). The 'what', 'why', and 'how' of needs assessment for adult EFL learners. Journal of Asia TEFL, 2(4), 1-16.

[12] Willis, J. (1996). Teaching English through English. England: Longman. 